\title{
EL ARCHIVO DEL MONASTERIO CISTERCIENSE DE NUESTRA SEÑORA DE BELMONTE (ASTURIAS, ESPAÑA) EN LA HISTORIOGRAFÍA MODERNA (1572-1807)*
}

\author{
POR \\ GUILLERMO FERNÁNDEZ ORTIZ ${ }^{1}$ \\ Universidad de Oviedo
}

\begin{abstract}
RESUMEN
En la Edad Moderna los archivos de las instituciones religiosas van a ser frecuentados por eruditos e historiadores para componer sus trabajos de carácter histórico. El objetivo del presente trabajo es estudiar, a través de un estudio de caso, cómo los historiadores de los siglos XVI a XIX acceden a un archivo monástico (el archivo del monasterio de Belmonte, Asturias, España), la accesibilidad a este archivo privado y el celo mostrado por los monjes del monasterio.
\end{abstract}

PALABRAS CLAVE: archivo; archivística; cistercienses; Santa María de Belmonte; historiografía.

\section{THE ARCHIVE OF CISTERCIAN ABBEY OF BELMONTE (ASTURIAS, SPAIN) IN THE HISTORIOGRAPHY OF THE MODERN AGE (1572-1807)}

\begin{abstract}
In the Modern Age, historians and erudits started to go to ecclesiastical archives to look for documents for their historial works. The objetive of this work is study how historians look documents up in the archive of cistercian abbey of Belmonte (Asturias, Spain), the accessibility to this private archive and how the monks allow or forbid this accessibility.
\end{abstract}

KEY WORDS: Archive; Archival Science; Cistercian; Abbey of Belmonte; Historiography.

Cómo CITAR ESTE ARTículo / CITATION: Fernández Ortiz, G. 2018. «El archivo del Monasterio Cisterciense de Nuestra Señora de Belmonte (Asturias, España) en la historiografía moderna (1572-1807)». Hispania Sacra 70, 141: 295-304. https://doi. org/10.3989/hs.2018.022

Recibido/Received 25-04-2016

Aceptado/Accepted 19-05-2016

\section{INTRODUCCIÓN}

Aunque la gestación de los archivos tiene lugar mucho tiempo atrás, en la Europa del siglo XVI la creciente pujanza de la cultura escrita los convierte en piezas y materia de especial atención, consecuencia directa de los cada vez más numerosos instrumentos que albergan y que los constituyen. Los archivos cobran en el siglo XVI un interés desconocido hasta entonces, al menos, y por vez primera, de modo generalizado. $Y$ en esta generalización radica la clave para comprender que nos hallamos ante el inicio de una nueva

Este trabajo se ha desarrollado en el marco de una investigación predoctoral financiada por FICYT.

1 fernandezguillermouo@gmail.com /

ORCID iD: http://orcid.org/0000-0002-4572-8236 realidad histórica, ante una nueva etapa en su evolución diacrónica. Son objeto de una fuerte reglamentación ${ }^{2}$ y sometidos a reorganización, pues contienen los instrumentos en los que figuran los derechos de cada institución o familia, así como aquellos otros vinculados a su diaria actividad. En los siglos de la Edad Moderna, los archivos son, tal y como ha señalado José Luis Rodríguez de Diego, archivos del Poder, de la Administración y de la Historia. ${ }^{3}$

2 Dos ejemplos conocidos y para ámbitos distintos son la instrucción para el arreglo del Archivo de Simancas y las normas archivísticas de las Ordenaciones de la Orden del Cister. Vid. Rodríguez de Diego 1989, y también Diffiniciones de la Orden de Cistel y Observancia de España 1561. Igualmente los capítulos de la Congregación de Valladolid se preocupan por el particular, vid. Pérez de Urbel 1959: VII.

3 Rodríguez de Diego 1998. 
Nos interesa esta última cualidad pues los pergaminos y papeles que albergan son fuente para las creaciones historiográficas que se comienzan entonces a componer ${ }^{4}$, aunque construcciones históricas a partir de documentos de archivo las conozcamos desde tiempo atrás. ${ }^{5}$ Así, a modo de ejemplo, y a propósito del buceo progresivo en los archivos por parte de los historiógrafos del siglo XVI, Ángel Canellas se refiere a "un movimiento general europeo». ${ }^{6}$ Podrían enumerarse un sinfín de autores al respecto, comenzando quizás por la figura de Zurita, cuya semblanza trazó el propio Canellas, y cuyas prospecciones archivísticas y acopio documental son hoy de sobra conocidas. ${ }^{7}$ Pero, para aproximarse a este espíritu dominante con mayor nitidez, para pulsar con cabal entendimiento la importancia que el documento de archivo adquiere entonces para el historiógrafo, quizás convenga dejar expresarse a alguno de ellos. El padre Sota, por ejemplo, acompañó su Crónica sobre los Príncipes de Asturias de un apéndice de documentos prologado con las siguientes palabras: «las escrituras de Archivos muy antiguos, y auténticos, son el alma de la Historia, por el fundamento infalible de la verdad que en ella se desea». ${ }^{8}$ Ya fray Prudencio de Sandoval en su Crónica del emperador Alfonso VII se había expresado a fines del Quinientos en términos similares al afirmar: «diré lo que hallo por escrituras, a quien doy entero crédito y tengo por guía para acertar con la verdad, que lo demás en cosas tan antiguas es hablar a tiento.$^{9} \mathrm{Y}$, finalmente, todavía a inicios del siglo XVIII son varias las voces que se manifiestan en el mismo sentido. Así se manifiesta uno de los censores del Ferreras convencido de Berganza ${ }^{10}$ : «son archivos, tradiciones, monumentos y autores que concordes establecen la más firme verdad de nuestra Historia». La prospección archivística de los Sota, Sandoval y Berganza y con ellos de tantos otros como Argaiz $^{11}$, Yepes $^{12}$ o el propio Zurita nos permite conocer las posibilidades de acceso a diferentes archivos privados. Mientras, de otro lado, la edición de documentos íntegros o las sucesivas referencias documentales que ofrecen dan puntual publicidad a los fondos que aquellos custodian. Sin embargo, esta apertura de los archivos a la producción historiográfica es uno de los aspectos menos estudiados. ${ }^{13}$

4 Lo expresa García Hernán 2006: 134. Así, es frecuente encontrar desde el siglo XVI anotaciones en manuscritos y códices que denuncian ese interés por asuntos históricos, Rodríguez Díaz 1994-1995: 1176.

5 El caso de la llamada Crónica Compostelana es muy conocido e inserta numerosos documentos pontificios entre otros. Falqué Rey 1994: 24.

6 Canellas López 1994: 17.

7 Canellas López 1986. Bautier 1968: 144.

8 Sota 1681: 623.

9 Sandoval 1600: 144.

10 Aprobación de fray Joaquín de Ania a Berganza (Berganza 1729).

11 Son continuas las referencias que da de los documentos a los que ha tenido acceso, en ocasiones a través de copia. Se pueden citar infinidad de ejemplos. He tomado algunos de Argaiz 1675: 110, 289, $319,324,378,387 \ldots$

12 Nadie podrá creer - dice en el prólogo del tomo I- sino es que lo experimente, el gran provecho y utilidad que se saca de ver y cotejar las escrituras originales, que están en los archivos que he dicho de León, principado de Asturias, reino de Galicia, Campos y Rioja, y la gran luz que dan a todas las historias. Citado en Pérez de Urbel 1959: XXIV.

13 Poncet 2010: 247-248. Disponemos de unas notas sobre la prospección en la catedral de León por parte de eruditos e historiadores, en Pérez Recio y Burón Castro 2006: 129-132.
El objetivo del presente estudio es ofrecer un análisis crítico de la imagen que sobre un archivo eclesiástico -el del monasterio de Nuestra Señora de Belmonte (Asturias, España) - componen los historiógrafos que, desde la segunda mitad del siglo XVI a finales del Antiguo Régimen jurídico, acuden al mismo para obtener los apuntamientos con que trazar su obra histórica. Del mismo modo, este estudio de caso permite fijar cronológicamente los inicios del interés de los historiadores por el material de archivo y las dificultades con que se encuentran. Aún más, se trata de perfilar algunos de los rasgos definitorios de la imagen del archivo en este período. Es decir, desde la temprana Edad Moderna se puede hablar de cierta accesibilidad a los archivos privados, en tanto que estos se constituyen en una "cantera» para la historia.

Como acabamos de anunciar, el objeto de nuestra atención será el archivo del cenobio de Santa María de Belmonte. Este fue, en los siglos de la Edad Moderna, un modesto monasterio de bernardos ${ }^{14}$, antigua fundación benedictina de tradición plenomedieval, enclavado en un angosto valle de la montaña centro-occidental asturiana, próximo a una de las rutas que comunicaba la orla cantábrica con la meseta castellana ${ }^{15}$, y que, desde mediados del siglo XVI, tras un proceso traumático, se integraba en la Observancia cisterciense de Castilla. ${ }^{16}$

De su archivo restan hoy únicamente algunos conjuntos documentales dispersos ${ }^{17}$, que si bien no son estimables en número ${ }^{18}$ y en variedad, sí que permiten intuir el volumen que llegó a generar, conservar, custodiar y organizar la institución durante su plurisecular historia, comprendida, grosso modo, entre mediados del siglo XII y el primer tercio del siglo XIX. Sin embargo, para aproximarse a su evolución diacrónica, para pulsar la percepción que del mismo tenían los monjes bajo cuya responsabilidad se encontraba, así como para conocer las posibilidades de acceso a un archivo que no dejaba de ser de uso y propiedad privado - pero, no al servicio exclusivo de la comunidad, responsable de su gestión, sino de toda la Congregación ${ }^{19}-$, las noticias suministradas por los historiógrafos de los siglos XVI a XIX adquieren singular relevancia y se convierten en testimonios sumamente expresivos para recrear la imagen de un archivo que únicamente con el análisis de sus propios fondos nunca llegaríamos a conformar.

14 Morales 1765: 113. Sandoval 1600: 144. Aunque en la transición del siglo XVI al XVII la cifra de religiosos debió de situarse en torno a la decena, a inicios de la década 1580 el número de monjes podría cifrarse cerca de la media docena, muy lejos de las cifras de las grandes abadías. AHN. Sección Clero. Regular. Cistercienses. Palazuelos. Valladolid. Libro 16521, folio 94ro.

15 Mañana Vázquez 2012.

16 Los orígenes de la Congregación han sido relatados en diversas ocasiones. Merecen destacarse los realizados por Pérez-Embid Wamba 1986; Martín 1953; y las páginas que dedica García Oro 1969. Más recientemente García Oro y Portela Silva 2001.

17 Sabemos que se encuentran en paradero desconocido libros de caja, libros de foros, cuadernos de apeos... y un conjunto sin duda sustancial de negocios escriturados en la Baja Edad Media sobre papel. La mayor parte de lo hoy conocido se conserva, no obstante, en el Archivo Histórico Nacional. Martínez Fernández 1979.

18 A excepción del conjunto de pergaminos.

19 La Observancia sufrió una progresiva centralización durante los reinados de Carlos V y Felipe II, ostentando el Capítulo General la potestad en prácticamente todas las facetas de la vida monacal o al menos interviniendo en su regulación y control. 
La pesquisa se extiende cronológicamente desde 1572, fecha en que el cronista Ambrosio de Morales realiza su visita a las iglesias y monasterios de León, Asturias y Galicia por orden de Felipe II, hasta 1807, cuando, en vísperas de la invasión francesa de la península, uno de los más activos corresponsales en Asturias para la formación del diccionario histórico y geográfico auspiciado por la Real Academia de la Historia, comunicaba, a su principal valedor, el académico Martínez Marina, haber recabado informaciones puntuales en Belmonte. Entre ambas fechas, son varios los eruditos e historiadores que ofrecen informaciones, bien sobre sus fondos, bien sobre su organización, en ocasiones contradictorias, en ocasiones sumamente expresivas.

\section{LA INACCESIBILIDAD DEL ARCHIVO}

Ambrosio de Morales, continuador de la crónica de España iniciada por Ocampo, llegó a recabar unas sucintas noticias sobre el monasterio de Belmonte, pero no logró verlas publicadas en vida. Las notas que tomó durante su viaje de 1571 y 1572 por el norte de la península, cumpliendo la misión encargada por el monarca para ver y reconocer, además de las fundaciones y dotaciones de los reyes, "los libros así de mano, como del molde antiguos, raros y exquisitos, que en las dichas iglesias y monasterios hay; y de todo hagais y nos traigais muy particular relación $»^{20}$ serían publicadas por el agustino Enrique Flórez finalizando el segundo tercio de siglo XVIII. Merece la pena reproducir el pasaje del Viage de Ambrosio de Morales tal y como salió a las prensas en 1765 , pero, en realidad, el testimonio hay que imaginarlo nota marginal de su manuscrito. ${ }^{21}$ Los apuntamientos sobre Belmonte, en efecto, aparecen descolocados, al figurar tras las apreciaciones sobre el monasterio de Villanueva de Oscos, en los confines occidentales de Asturias. Escribe el jerónimo: «BELMONTE también es Casa pequeña de Cister en Asturias. No hay en ella cosa, ni memoria que notar, por no tener escrituras». ${ }^{22}$

Doscientos años más tarde, en 1807, Ramón Baragaña Alonso, cura de la fábrica de armas de Trubia y uno de los colaboradores más activos en la realización del diccionario histórico regional anhelado por la Real Academia de la Historia, informaba, por correspondencia privada, al responsable del proyecto, el académico Martínez Marina, de su viaje a Belmonte en los siguiente términos: «reconocí el sitio a todo mi placer y estoi mui seguro de quanto digo [...]. Pregunté al padre abad, que es bello sugeto, si havía en el archibo papeles que pudiesen contribuir a ilustrar la historia y me contestó que no les quedó ninguno a resultas de el poco cuidado que tubieron los antecesores». Únicamente pudo consultar un libro de becerro. ${ }^{23}$

Ahora bien, pese a la coincidente opinión de ambos, que bien pudiera sugerir una exacta descripción de la realidad, lo realmente cierto es que ni el testimonio de uno ni el del

\footnotetext{
20 Recogido en Mestre Sanchis 2003: 241. Morales 1765: 2-3.

21 Morales 1765.

22 Morales 1765: 113
}

23 Biblioteca de la Real Academia de la Historia. Papeles de Martínez Marina. 9-6038. Carpeta no 1. Corresponsales. Carta de Ramón Baragaña, fechada en Trubia a 17 de octubre de 1807. El contenido de parte de la carta había sido ya dado a conocer por Pérez de Castro 1959: 145. otro se aproximan levemente a esta, sino que la auténtica realidad que tales testimonios permiten intuir es bien distinta. Veamos el porqué de esta afirmación.

En primer lugar, un hecho irrefutable: según los testimonios que conocíamos, del viejo archivo monástico de Belmonte se conservaban en Madrid más de 300 instrumentos de cronología medieval, siendo la procedencia de los mismos el referido fondo. ${ }^{24}$ Junto a ellos, hay algún que otro instrumento en papel, datado, bien en el siglo $\mathrm{XV}$, ya en los primeros tres cuartos del siglo $\mathrm{XVI}^{25}, \mathrm{y}$, numerosos, antes de 1807, cuando Baragaña toma sus apuntamientos.

En segundo lugar, porque los monjes de Belmonte, en según qué fechas, pusieron especial atención en el cuidado de su archivo: ya procurándose la organización de sus fondos, ya preocupándose por la guarda de escrituras, o ya interesándose por la obtención de copias de aquéllas que hubieran desaparecido por motivos diversos...

$Y$, en última instancia, porque son varios los historiadores que ofrecen notas sobre el archivo de Belmonte netamente opuestas a las suministradas por los anteriores. Y son estas las que nos permiten conocer, bien la organización de los fondos, bien la cuidada política de gestión documental llevada a cabo por los monjes, bien reconocer las facilidades de acceso a la consulta de los fondos de archivo. En resumen, nos permiten recrear una imagen diferente del archivo monástico.

Dicho de otro modo, las afirmaciones de Morales y de Baragaña no son inútiles, sino todo lo contrario, son testimonio inequívoco de las dificultades de acceso a un archivo privado, del nivel semioculto, de la esfera de lo semivisible, en el que se halla este. El recelo de los responsables del archivo - de aquellos monjes archiveros que aparecen ampliamente reconocidos como tales desde inicios del siglo XVII entre los bernardos castellanos ${ }^{26}$, custodios de la documentación de gestión y de los títulos de propiedad de la comunidad, dificultó el conocimiento exacto de los fondos monásticos a aquellos historiógrafos que se interesaron por obtener informaciones para sus composiciones. Aún más, fue esta una actitud generalizada, actitud que compartía toda la comunidad, desde el último profeso que la integraba hasta el abad de la misma que, bien durante un trienio, bien durante un cuatrienio, regía los destinos del convento del cual era responsable y al final de cuyo mandato debía rendir cuentas de lo realizado.

En todo caso, el hecho es diáfano: el archivo pertenece a la esfera de lo semivisible y el acceso al mismo no está

${ }^{24}$ Así lo expresaba Miguel Vigil quien supo de ellos cuando aún paraban en la Biblioteca de la Real Academia de la Historia. Miguel Vigil 1887: 436. Actualmente estamos trabajando en la elaboración de un catálogo de escrituras medievales de dicho archivo y hasta el momento hemos logrado documentar cómo el número de acciones jurídicas que tuvieron refrendo documental en instrumentos del fondo de Belmonte supera largamente la cifra de 450.

25 Apenas se conservan instrumentos en papel de los siglos XIV, XV y primera mitad del siglo XVI, si bien hay noticias posteriores que permiten imaginar el volumen de pérdidas.

26 Vid. por ejemplo: Diffiniciones hechas en el Capítulo General que se celebró en el monasterio de Santa María la Real de Palaçuelos à cinco de mayo del año de 1611 en el qual salió por General Reformador nuestro Reverendíssimo padre maestro fray Philippe de Tassis, hijo del real monasterio de Herrera. Definición no 46. 
permitido a todo el mundo. Más aún si el interesado en acceder a sus fondos, si quien desea conocer los monumentos que alberga, representa a una persona o institución cuyas actuaciones no resultan gratas para el propietario del archivo. Morales y Baragaña se encuentran en esta situación. El primero, cronista regio, llega a Asturias por mandato de Felipe II con el fin de realizar averiguaciones al servicio de la Corona, y lo hace en un momento en el que los intentos «desamortizadores» de mediados de siglo son algo más que un recuerdo. ${ }^{27}$ De hecho, apenas unos años más tarde se produciría una nueva tentativa, en este caso de mucho mayor alcance. El segundo entabla contacto con los monjes de Belmonte hacia 1807, en el marco del proyecto que emprende la Academia de la Historia ${ }^{28}$ : en aquel momento hacía apenas un par de años que el entonces abad, fray Baltasar Muñiz, se había puesto en contacto con el comisionado en Asturias, por orden de la Corona, para la «enagenación de las fincas eclesiásticas en esta diócesis [y para que] se le remita por esta comunidad una razón circunstanciada de todos los bienes que por qualesquiera título posea [...]». ${ }^{29}$ Esta generación de religiosos estaba viendo cómo, desde 1798, Godoy y Carlos IV habían ido ampliando su campaña desamortizadora. ${ }^{30}$

\section{LAS VENTAJAS DE LOS ERUDITOS AL SERVICIO DE LA OBSERVANCIA CASTELLANA}

Muchas menos trabas y dificultades se encontraron aquellos que desempeñaron su labor publicística bajo los auspicios de la Observancia cisterciense castellana. Es decir, hubo quienes contaron en sus empresas escriturarias con el respaldo del Capítulo General. Eso cuando no tuvieron por amparo el sentir general de la Congregación. Fijémonos, concretamente, en los casos de fray Ángel Manrique en el primer tercio del siglo XVII y de fray Roberto Muñiz a finales del Setecientos, ambos con una sólida formación y prolífica carrera como escritores. Y ambos, además, según parece, estuvieron en Belmonte. De la estancia del primero no duda Leopoldo González ${ }^{31}$ y lo pueden corroborar los testimonios que más abajo ofrecemos. De la etapa belmontina del segundo tenemos el valioso testimonio de Carlos González Posada, que lo conoció como conventual en el colegio asturiano. $^{32}$

Manrique es poco pródigo en informaciones sobre el archivo, pero las noticias que transmite nos permiten intuir las fuentes de que se valió, es decir, de qué monumentos de los allí custodiados se sirvió para su obra histórica. En primer lugar, cabe afirmar, con total seguridad, que los testimonios

27 Se refieren al particular: Cuartas Rivero 1982: 465-466; Menéndez González 1983: 492-493. La monografía fundamental es de Faya Díaz 1993: 14. Publican los resultados de la averiguación Alonso Martín y Palacio Sánchez-Izquierdo 1993: 141.

28 Conservamos unas 14 cartas, comprendidas cronológicamente entre mayo de 1805 y octubre de 1807. Biblioteca de la Real Academia de la Historia. Papeles de Martínez Marina. 9-6038. Carpeta oo 1. Corresponsales.

${ }_{29}$ AHN. Sección Clero. Regular. Cistercienses. Belmonte (Oviedo). Legajo 4937. Carpetilla. Desamortización. Enajenación de bienes eclesiásticos y oficios y lista de las rentas del monasterio. 1805.

30 Moro Barreñada 1986: 97-98. Rueda Hernanz 1997: 30-31.

31 González Gutiérrez 1993: 9.

32 González Posada 1989: 114. que ofrece de Belmonte tan solo son parcialmente desconocidos. Ahora bien, además de episodios ya dados a la estampa por otros autores como Yepes o Sandoval, Manrique da los nombres de los primeros abades de la comunidad y ofrece traslado de la lápida consagratoria de la primitiva iglesia del cenobio, cuestiones de las que hasta la fecha nadie había transmitido información alguna. Por otro lado, él mismo refiere cómo accedió al archivo del cenobio. Ahora bien, pudo manejar únicamente el becerro nuevo del monasterio. Ni consultó los viejos pergaminos medievales ni copió la lápida fundacional del epígrafe original. Sabemos que en otros centros prefirió consultar libros modernos de administración que no documento a documento del archivo. ${ }^{33}$ La transcripción de la lápida que ofreció presenta la misma lectura de numerales de la data que la copiada en el libro becerro del monasterio, y ambas difieren de la que Jovellanos pudo leer del epígrafe original a fines del Setecientos. Además, la nómina de abades que ofrece bien puede estar tomada de dicho códice. ${ }^{34}$ Las últimas noticias que facilita Manrique son las de la incorporación del cenobio a la Observancia castellana, siendo más pródigo en informaciones que Sandoval o Carvallo. ${ }^{35}$ Es entonces cuando acredita tener conocimiento de noticias del archivo, informaciones que se hallaban compendiadas en el becerro. ${ }^{36}$

El testimonio de Muñiz es bien distinto. Este «portento de erudición»-según feliz expresión de Constantino Suárez ${ }^{37}$ - era asturiano, natural del barrio de Sabugo de Avilés $^{38}$, y ya desde joven pudo trabar contacto con los monjes de Belmonte, cuando con ocasión de la romería de Santiago de Naveces se desplazaba con su familia al santuario enclavado en la comarca, en el cual la reliquia del Santo era guardada con celo por los monjes bernardos de la cuenca del Pigüeña. Fue autor también prolífico y escribió dos obras de importancia singular: su Médula histórica en varios volúmenes y la Biblioteca cisterciense. Es este texto el que ahora nos interesa, no tanto por ser juzgada como su obra cumbre ${ }^{39}$, como por el hecho de ser en ella en la que se refiere al monasterio de Belmonte.

En esta obra, que enlaza en su concepto y estructura con una línea con tradición en la bibliografía hispana, como lo eran los repertorios bibliográficos de escritores de órdenes religiosas ${ }^{40}$, el monje asturiano arroja nuevas informaciones y juicios sobre Belmonte, su archivo y sus reliquias, todas desconocidas hasta entonces. Pero no ofrece estas noticias en las pequeñas biografías que dedica a cada uno de los autores que compendia, acompañados de su producción bibliográfica, tanto impresa como manuscrita, sino en las notas introductorias al cuerpo del texto. Es decir, su juicio sobre el archivo del cenobio asturiano no se halla en el cuerpo de ninguna de sus obras, sino en la pieza prologal a

33 Finestres y de Monsalvo 1753: 12.

34 Manrique 1649: 413-414.

35 Recientemente Javier de Santiago ha vuelto a destacar la labor de Manrique. Santiago Fernández 2012: 75. Sobre su personalidad y su recopilación de epígrafes medievales es de máximo interés: Martín López 2011.

36 Manrique 1649: 637.

37 Suárez Fernández 1956: 448.

38 Garralda García 1970: 332.

39 Así se expresó Yáñez Neira 2003: 68.

40 Mestre Sanchís 2003: 250. 
la Biblioteca cisterciense. Esto es en una pieza paratextual que precede a su nómina de escritores cistercienses y en la que trata de diversas materias con la libertad que le ofrece el marco elegido.

Ofrece, por lo tanto, estas informaciones sobre Belmonte en el prólogo a su Biblioteca junto a otras alusivas a varios monasterios del Císter que, a juicio del asturiano, no fueron retratados con veracidad en el Viage de Ambrosio de Morales. De ahí que precisamente se refiera al contenido del relicario y al archivo, pues ambos salieron malparados en las líneas que sobre Belmonte escribió el cronista cordobés. En los siguientes términos se expresó a propósito de las palabras de Morales:

Los descuidos del viajante [...] [que] omitió en solo los monasterios de nuestra Congregación [de San Bernardo de Castilla], con la expresión magisteriosa de que no tienen Reliquias, ni Libros: prueba clara de que no se informó á cerca de las cosas de nuestros Monasterios ò que se informó de personas poco instruidas en ellas. [...] En Belmonte, donde confiesa no llegó, y que nada hay que notar por no tener Escrituras, hay no solo Escrituras, Donaciones, y Privilegios desde [...] que se fundó, un Archivo de los más bien coordinados [...]. ${ }^{41}$

Por lo tanto, el archivo que llegó a ver Muñiz en Belmonte estaba cabalmente organizado y tenía un número considerable de escrituras, algunas de las cuales se remontaban a tiempos de la fundación. Y, en fin, estamos ante un archivo en el que el acceso a sus instrumentos, especialmente a los manuales de época moderna, le está permitido tanto a los miembros de la comunidad monástica como a los estudiosos de la Orden, pero que, como habíamos visto, tampoco había sido su consulta limitada a personajes ajenos a la Observancia.

\section{UN ARCHIVO ACCESIBLE}

Otros afamados polígrafos nos van a permitir redondear las informaciones que ofrecen los anteriores y con ello completar la visión foránea de un archivo monástico cuyas posibilidades de consulta estaban limitadas.

En torno a unos veinte años más tarde a la fecha del viaje de Morales, es decir, en la última década del Quinientos, fray Prudencio de Sandoval, monje benedictino que todavía no había alcanzado el status de cronista regio ${ }^{42}$, hizo públicos en su crónica sobre el ínclito emperador Alfonso VII los hitos más destacados de la historia del cenobio de Belmonte: 1) la fundación, valiéndose para ello del contenido del documento tenido desde entonces por fundacional, y 2) la incorporación a la Observancia castellana. ${ }^{43}$ No se detiene el benedictino en enumerar parte de los fondos ni en describir el estado o la organización del archivo, pero su testimonio es la prueba fehaciente de que se le ha franqueado el acceso al mismo durante su estancia en Asturias, o, al menos, que se le ha facilitado información desde el monasterio. Así lo afirma el padre Yepes: «del monasterio de Santa María de Belmonte tampoco he visto su Archivo, ni he tenido papeles.

41 Muñiz 1793.

42 Sobre el oficio de cronista regio pueden verse las páginas que le dedica García Hernán 2006: 127 y ss.

43 Sandoval 1600: 144.
Debiólos tener el Señor Obispo de Pamplona, Don Fray Prudencio de Sandoval». ${ }^{44}$ Además, puede corroborarse su testimonio por una doble vía.

Por un lado, a Asturias se desplazó Sandoval en cierta ocasión, según consignan todos sus biógrafos. ${ }^{45}$ Parece fuera de toda duda que, al menos, estuvo en Oviedo ${ }^{46}$ donde consultó documentación en diferentes instituciones. Además de en la catedral de San Salvador accedió a los materiales del archivo monástico del centro benedictino de San Vicente ${ }^{47}$ y a los fondos del archivo de la ciudad de Oviedo. ${ }^{48} \mathrm{Y}$, por otro lado, Sandoval sabía que el monasterio de Belmonte había sido fundado en el lugar de "Lapedo, que de doscientos años a esta parte, poco más o menos, se llama de Belmonte». ${ }^{49}$

El pasaje podría pasar perfectamente desapercibido, pero, la del benedictino, supone una sutil apreciación, ya que, también a fines del siglo XVI, unos pocos años antes de que la crónica del emperador saliera a la estampa, un cisterciense, fray Jerónimo de Llamas, religioso de reconocida valía intelectual entre sus coetáneos, a la hora de organizar los materiales del archivo de Carracedo, se encuentra con que del cenobio berciano dependieron en la Edad Media varias casas. Entre estas estaban «el monasterio de Belmonte [que] fue filiación de este monasterio" y "otro monasterio tuvo este monasterio sancto por filiación que se llamó Lapedo. Y de esto ay mucha certeza. $Y$ aunque no ay de ello special scriptura [...]. Yo confieso que no é podido hasta aora averiguar dónde caía este monasterio, aunque lo é procurado»..$^{50}$ Por lo tanto, si en el seno de la Observancia castellana, dentro de los círculos de mayor calado intelectual se desconocía que Lapedo y Belmonte eran en realidad un mismo cenobio y si además tenemos en cuenta que el cambio de denominación hacia mediados del siglo XIII está bien atestiguado en la documentación medieval de su archivo $^{51}$, parece irrefutable que Sandoval manejó las escrituras de Belmonte, bien directamente de su archivo o bien a través de las informaciones o copias que le fueron facilitadas desde la casa monástica. Pero, en todo caso, lo innegable es que el archivo no le fue vetado, y que, de un modo u otro, tuvo acceso a unos contenidos a los que logró dar publicidad.

Sandoval no es un caso aislado. Pocos años más tarde de la estancia del benedictino en Belmonte, la abadía acogería la visita de Luis Alfonso de Carvallo. Este asturiano de origen, autor de la primera historia de Asturias que a nosotros ha llegado, y personaje de prestigio en la región a inicios del

\section{Yepes 1609.}

45 En realidad, todos siguen la afirmación de Benito Montejo. Vid. nota infra. Ofrece datos nuevos sobre sus viajes García Hernán 2004: 152-153.

46 No sabemos de momento la fecha exacta de la estancia de Sandoval en Oviedo. Carlos Cid no duda de su venida Cid Priego 1990: 777 y 780 . Aunque este autor no indica referencia alguna, la noticia de los viajes de Sandoval, la toma, fuera de toda dudas, de Montejo 1792: 17-18.

47 Sandoval 1600: 15 y 165.

48 Ibídem: 118.

49 Ibídem: 144.

50 Llamas 1993: 185 y 195.

51 Son numersas las referencias que se hallan en la documentación del monasterio. AHN. Sección Clero. Regular. Cistercienses. Belmonte. Carpetas 1573 nㅇ 8; 1575 n오 5; 1576 n으 20, entre otros. 
siglo XVII reconoció de primera mano un buen número de archivos y entre ellos el que es objeto de nuestro interés..$^{52}$ Rector del colegio de San Gregorio de Oviedo ${ }^{53}$, hacia $1613^{54}$, terminó su Historia de las Antigüedades y Cosas Memorables del Principado de Asturias. Se trata de una historia religiosa de la región en la que su autor no descuidó el estudio de casas solariegas, blasones y genealogías. ${ }^{55}$ Además de las fuentes de archivo, Carvallo se muestra buen conocedor de la producción historiográfica del momento y aún a los clásicos latinos. Convive en Oviedo y forma grupo con diversas personalidades con inquietudes intelectuales como Marañón de Espinosa ${ }^{56}$ o el médico Martín Sánchez. ${ }^{57}$ Pero, a Carvallo por lo que más se le estima hoy es porque lleva a cabo una labor de prospección documental por distintos archivos privados. Es esta la que le lleva a Belmonte en algún momento entre 1605 y 1613. Prospecta el archivo, reconoce varios diplomas y toma diversos apuntamientos. ${ }^{58}$ Estos serán usados en esta obra y en sus Linajes asturianos, que también se le atribuye. ${ }^{59}$ En 1695 , más de 80 años después de su concepción, las Antigüedades y Cosas Memorables fueron finalmente publicadas. Este "partho póstumo a su autor», según expresión de Trelles Villademoros, circuló manuscrito durante largo tiempo. ${ }^{60} \mathrm{Y}$, en estas copias, según Fuertes Acevedo ${ }^{61}$ o el propio Trelles ${ }^{62}$, se introdujeron

52 El último en referirse a ello: Calleja Puerta 2007: 91-121.

53 Así escribe el propio Carvallo: «Fundó [Valdés-Salas] en la Ciudad de Oviedo el colegio de San Gregorio, uno de los mejores Estudios de Latinidad que ay en España (sino es que por estar a mi cargo al presente aya decaído)». Carvallo 1988: 464.

54 Esta fecha se ha venido repitiendo como la más probable. Fue Fuertes Acevedo quien la apuntó a partir de un manuscrito conservado en la Real Academia de la Historia: Fuertes Acevedo 1878: 291.

55 Carvallo 1988.

56 A propósito de los primeros pobladores de Asturias, recoge la opinión de Espinosa sobre el particular: «[...] según piensa el Arcediano de Tineo, hombre docto en griego». Ibídem: 21 y 23.

57 Del doctor Martín Sánchez, catedrático de Matemáticas, se ha repetido constantemente que ha sido autor de un catálogo de planta medicinales, que sin embargo nadie ha visto nunca, a partir de la referencia que de él hace Carvallo; Así, por ejemplo: Fernández Ruiz 1965 130-131. Pero en realidad Carvallo nada escribe de un catálogo de plantas impreso o manuscrito, sino que "el propio doctor me ha dicho»: Carvallo 1988: 10. La referencia al posible catálogo procede de la noticia que ofrece Risco, pero este menciona el catálogo como obra de Carvallo, a quien Martín Sánchez facilitó la noticia: Risco 1789: 22.

Parece claro, a partir de esa referencia, que Carvallo le trató. Ambos vivieron en Oviedo a comienzos del siglo XVII. Martín Sánchez, médico de la ciudad, en 16 de abril de 1607 le pide al ayuntamiento sus emolumentos del año anterior (Archivo Municipal de Oviedo (AMO). A16. Libro de Acuerdos del Ayuntamiento de Oviedo, folio 371ro y vo). Un ayuntamiento que en 20 de octubre de 1606 había acordado nombrarle para la cátedra de Matemáticas (AMO. A15. Libro de Acuerdos del Ayuntamiento de Oviedo, 20 de octubre de 1606). Fue, de hecho, el primer catedrático de esta materia de la Universidad, que abriría sus puertas en septiembre de 1608: Canella Secades 1903-1904: 43.

58 Carvallo 1988: 328, 332, 344, 355, 388 y 457.

59 Manuel Caballero dispuso de ejemplar de los linajes de Carvallo: Caballero 1995: 49.

60 El propio Manuel Caballero en una ocasión en que cita la obra de Carvallo se refiere a ella como del «padre Luis Alfonso ( ) su manuscrito historial». Caballero 1995: 143. Sobre la circulación de manuscritos en el período: Bouzá Álvarez 2001. También Poncet 2009: 408.

61 Fuertes Acevedo 1878: 291-292.

62 A propósito de las Antigüedades afirma: «no es de admirar se hallen la noticias, que reconoció [...] mal colocadas y torcidas, quizà azia donde dictaba la passión, de los que manejaron, después de muerto, sus papeles [...]»: Trelles Villademoros 1736: 3. modificaciones al original. De modo que, a tenor de lo que expresan unos y otros, parece que la versión que llegó a la imprenta no fue la genuina de su autor. ${ }^{63}$

La versión impresa de esta obra se articulaba en tres grandes bloques y sucesivos capítulos y recogía los textos referentes al monasterio de Belmonte en su tercer apartado, dedicado a aquella Asturias que ya había dejado de ser sede de la monarquía. Carvallo, al margen de las informaciones que toma de la historiografía de su época, se vale de documentanción inédita para elaborar sus líneas sobre Belmonte como venimos insistiendo. Se detiene largamente en la figura del fundador, Pedro Alfonso, recogiendo las informaciones que le suministra la obra de Sandoval, y en la dotación que hace del cenobio y así como en su testamento. Es el primero que describe con detenimiento su emplazamiento, y menciona el lugar en el que se levanta; identifica también Belmonte con Lapedo, insinúa una fundación anterior y enumera algunas de las reliquias del monasterio. Para todo ello se valió de la documentación del archivo, de alguno de cuyos contenidos da noticia. ${ }^{64}$

Ciertamente es este último el aspecto que más nos interesa. En primer lugar porque «este monasterio es el de Belmonte, como he visto por muchas escrituras antiguas de aquel Monasterio, en todas las quales se llama de Lapedo, hasta los años de 1254, que se començó à llamar Belmonte» y en segundo porque a la hora de citar los instrumentos que maneja de Belmonte anota siempre su cota archivística. ${ }^{65}$ Por Carvallo sabemos pues que, al menos, desde inicios del siglo XVII no era despreciable el conjunto documental del monasterio y que los instrumentos de su archivo se hallaban distribuidos en cajones. Es decir, se trataba de un fondo organizado. De este modo, el archivo bien coordinado del que nos habla Muñiz a mediados del siglo XVIII ya era tal desde inicios del XVII. Y, en fin, nos encontramos de nuevo con un archivo accesible al foráneo, al investigador de prestigio, al erudito que solicita de los religiosos encargados del mismo las informaciones que precisa para su obra histórica. ${ }^{66}$

Finalmente, en la última década del siglo XVIII es Jovellanos el que con motivo de su profesión en la orden de Alcántara se desplaza a Belmonte. ${ }^{67}$ La estancia del polígrafo gijonés en el monasterio no se ciñe, sin embargo, al acto religioso sino que aprovecha la oportunidad que le brinda el viaje para tomar unas cuantas notas sobre todo aquello que ve: el camino, los ingenios... y, como no podía ser de otra manera en ese hombre que quiere verlo todo, en ese «empedernido reconocedor de archivos y allegador

63 En el prólogo puede leerse: «Esta obra póstuma, que yazía sepultada en la obscuridad [...] poco menos ha de un siglo que anda manuscripta [...]»: Carvallo 1988: 464. También se hizo eco de ello el canónigo González Posada 1989: 93.

64 Carvallo 1988: 326.

65 Por ejemplo, de una donación de Aldera González especifica cómo se encontraba en el cajón 16 nำ6. Mientras, de la donación de Martín Fernández en Ambasmestas aclara como se guardaba en el cajón 7 como no 1 . Carvallo 1988: 332 y 457.

66 En el trienio del padre Vicente Encalada encontramos, según Manrique, una de las primeras disposiciones de cara a crear el puesto de archivero. Manrique 1659: 370.

67 Sobre la decisión de profesar en la Orden de Alcántara: Jovellanos 1985: 180-181. Carta de Jovellanos a Manuel de Aizpún y Redín. Mayo de 1780 . 
de copias de documentos antiguos», según afortunada expresión de Eutimio Sastre ${ }^{68}$, el archivo.

La tarea de prospección archivística y los numerosos apuntamientos que toma en Belmonte no desmerecen el proceder del ilustrado gijonés en otros centros religiosos (catedral de Astorga, Cornellana, Valdediós, San Pedro de Teverga...). La estancia en este centro le permitirá consultar el material de un archivo que los monjes le franquean sin oposición. Allí toma diversos apuntes, inicia sus primeras transcripciones y anota también las impresiones que le producen los instrumentos que le proporcionan.

Así, nada más llegar al monasterio, tras anotar en el diario las apreciaciones del viaje se «echa de bruces sobre un librote manuscrito que acaba de traerme el padre abad". Es decir, los monjes le ofrecen manejar el libro de becerro, aquel que habían manejado Carvallo y Manrique, aquel que unos años más tarde consultaría también Baragaña. Jovellanos nos ofrece su propia descripción del códice y emite su propia opinión sobre el valor que le merece. El pasaje es lo suficientemente expresivo:

El gran libro, con el nombre de Tumbo, es un índice de los documentos del archivo por materias, escrito magnificamente en papel marquilla y formado en 1604 [...]. Después de un largo prólogo y de copiar los versos de Sandoval en la Historia de Alfonso VII, hablando del fundador, el conde don Pedro Alfonso, empieza por una historia de la fundación, harto confusa, así por haber equivocado las notas numerales leyendo en los privilegios la $X^{L}$ por sólo diez y no por cuarenta, según se debía, como por no haber combinado las escrituras de diferentes tiempos; ellas darán la historia verdadera. [...] trae una serie de los abades; mas, [...]. Copia asimismo la inscripción de la antigua iglesia, que yo copiaré aparte, puesto que dicen no estar legible, aunque haré por comprobarla, a lo menos en cuanto a nombres y fechas. [...]. ${ }^{69}$

El día siguiente, víspera de su profesión, le proporciona el tiempo suficiente para pasear por el entorno, para ver con sus propios ojos la lápida fundacional y, lo que más nos interesa a nosotros, manejar los instrumentos del archivo monástico. La mañana la pasa en el archivo («al archivo, y en él toda la mañana: hay buenas cosas, y se copiará cuanto el tiempo permita»). Por la tarde volverá a tomar apuntamientos y en la tarea de transcribir documentos tendrá ocupado a su secretario.

Además de copiar un buen puñado de papeles y pergaminos nos ofrece el estado en el que se encuentran algunos de ellos. De los privilegios de concesión de coto de Alfonso VII nos dice que «hai tres originales, los dos vellamente conservados en pergamino, el otro no tan bien y a más hai también una copia en pergamino». De un privilegio de Enrique II expone que «está original en pergamino, bien conservado y con sello de plomo" y en los mismos términos vuelve a referirse a uno de Enrique III. ${ }^{70}$ Además, cotejando los documentos de los que ofrece noticia con los que actualmente se conservan, podemos intuir pérdidas que se han producido en los últimos treinta años de vida regular en Belmonte, vinculadas a los traumáticos acontecimientos del primer tercio del siglo XIX que afectan de un modo u otro al monasterio.

\footnotetext{
68 Sastre Santos 1995: 6.

69 Jovellanos 1994.

70 Jovellanos 1948: 242 y 252-253.
}

Por otro lado, Jovellanos no disecciona únicamente el becerro del monasterio, sino que también nos da noticia de otro instrumento de descripción del archivo: un inventario del mismo, a buen seguro aquel del que tenemos noticia de su confección a inicios del siglo XVII. ${ }^{71}$ Así, a propósito de un fragmento de las pesquisas de Alfonso IX ${ }^{72}$, que paraba entonces en el archivo monástico, afirma el prócer gijonés: «en un índice moderno del archivo se dice que de esta pesquisa y división general de heredamientos se hizo un libro y se depositó en San Vicente de Oviedo y aún se supone que existe allí»». ${ }^{73}$

Finalmente, Jovellanos nos da una noticia de sumo interés sobre la salida de documentos del archivo. Como bien sabemos, en los siglos de la Edad Moderna son continuas las disposiciones para que las escrituras no abandonen el archivo o, en su defecto, para regular dichas salidas. Como por uno u otro motivo resulta necesario sacar algunos instrumentos, el primer aspecto sobre el que se reglamenta es sobre la necesidad de dejar constancia de qué documento, por quién y porqué motivo ha sido extraído del archivo. Así surgen los primeros registros en los que se da cuenta de este trasiego de escrituras. ${ }^{74}$

En Belmonte, como no podía ser de otra manera, algunos documentos salieron para sustanciar pleitos en Chancillería y, más tardiamente, en la Audiencia de Oviedo; mientras, otros fueron a parar a archivos particulares fruto de los negocios fundiarios del monasterio. Del mismo modo, algunos instrumentos fueron manejados para la elaboración de apeos y, fruto de este quehacer, su salida del archivo se antojó inevitable, más aún si quien debía encargarse de dicho deslinde no era el propio cenobio sino el particular al que se había aforado la propiedad fundiaria. Así se especificaba en el foro que los monjes de Belmonte concertaron con la casa de Maldonado a propósito de ciertos bienes que la comunidad tenía distribuidos por varios puntos del concejo de Tineo. Es Jovellanos el que nos informa sobre el particular, al habernos transmitido copia de un instrumento del archivo monástico del que se sacó traslado con esta finalidad:

[...] Se hizo foro a la casa de Maldonado, quien paga en cada un año y por día de San Martín veinte y dos reales vellón puestos sin desquento alguno a su costa, por el referido tiempo, en este colegio, y con la obligación de apearlos y executoriarlos dicha casa a sus expensas en el término de quatro años, entregando un tanto authorizado de todo a este colegio sin que este tenga otra obligación que la de franquear los instrumentos de pertenencia a la propiedad de dichos bienes. ${ }^{75}$

El pequeño cuadernillo en papel, tamaño folio, en el que se contiene esta información se conserva aún en el Archivo Histórico Nacional e incluía la copia ya sacada de los instrumentos que debían utilizarse para el apeo. ${ }^{76}$

\footnotetext{
71 Archivo Histórico de Asturias (AHA). Fondo Antigua Diputación Provincial. Caja 383. [sin foliación original].

72 No es la única referencia a esta averiguación del monarca en la diplomática asturiana. Vid. Ruiz de la Peña Solar y Sanz Fuentes 1991: 74-75.

73 Jovellanos 1948: 263-264.

74 Castillo Gómez 1997: 258.

75 Jovellanos 1948: 271.

76 AHN. Sección Clero. Regular. Cistercienses. Belmonte (Oviedo). Legajo 4937. Carpeta: papeles testamentarios.
} 


\section{CONCLUSIONES}

El archivo del centro religioso está, en principio, reservado a las actividades de gobierno propias de la institución, misión primera para la que ha sido concebida su propia existencia. Esta naturaleza es la que determina su pertenencia a la esfera de lo privado, de lo semivisible. Nadie más que los miembros de la congregación, representados en las personas responsables de su cuidado en el monasterio - el archivero del mismo, el abad...-, tienen acceso a sus contenidos.

De este modo, cuando una persona ajena a la institución desea manejar instrumentos del mismo puede encontrarse con el rechazo de la comunidad: ya con una negativa rotunda, ya, como hemos documentado en Belmonte con la visita de Baragaña, con una insincera receptividad.

No obstante, en otros casos, tenemos bien atestiguado el acceso al material de archivo por parte de personas ajenas a la congregación. Al respecto, es paradigmático el caso de Luis Alfonso de Carvallo que manejó a su gusto los instrumentos del fondo belmontino en la primera década del Seiscientos. No obstante, el archivo le fue franqueado sin ninguna dificultad tanto por el prestigio personal de que gozaba en la región como por el exacto conocimiento que los monjes de Belmonte tenían de la amplia actividad de prospección archivística que este estaba llevando a cabo con fines a la elaboración de una obra histórica. ${ }^{77}$

En lo que atañe al acceso al fondo cabe señalar dos aspectos. En primer lugar está claro que el celo en la custodia del archivo no fue siempre el mismo. No todos los archiveros de la comunidad de Belmonte $-\mathrm{y}$ como en Belmonte en el resto de centros eclesiásticos- pusieron el mismo empeño en su quehacer. Hubo celosos guardianes del archivo y otros que no pusieron tanto reparo en facilitar el acceso a los documentos custodiados.

En segunda instancia, está la posición que ocupa el interesado en consultar y conocer los fondos del archivo. En este sentido cabe añadir, además, que la oposición a Morales y a Baragaña está mediatizada por la vinculación con la Corona o con el poder central de las actividades que ambos vienen realizando. De hecho, en el caso del primero, antes de partir en su viaje, el propio Morales había comunicado sus intenciones a las instancias superiores de bernardos y benedictinos. Es decir, la oposición no es solo al desempeño del individuo sino al cuerpo al que se le asocia. En este sentido cabe recordar el intento de venta de jurisdicciones eclesiásticas o de medidas «desamortizadoras» por parte del poder real en tiempos inmediatos a las pesquisas de los anteriores. Finalmente, se puede mostrar cómo estos no fueron casos únicos, pues, incluso, el propio Jovellanos, que había ya reconocido decenas de archivos, se encuentra con la negativa de las monjas de Otero que sospechaban de las intenciones del asturiano, quien entonces volvía de Salamanca de formar la instrucción para el archivo del Sancti Spiritus.

Los testimonios de los eruditos de los siglos XVI al XIX nos permiten componer la imagen de un archivo que únicamente con los fondos de este nunca llegaríamos a conformar. Aunque sus informaciones no sean acertadas o veraces no por ello son

77 La escasa fortuna que los investigadores «independientes» tendrían para acceder a la documentación custodiada en archivos privados fue señalada por Pomian 1972: 116. inútiles, sino más bien todo lo contrario. No obstante, está claro que sus testimonios deben interpretarse con cautela y siempre cotejándolos con otro tipo de informaciones con el fin de no extraer conclusiones erróneas.

A la luz de todos los pasajes que ofrecen los anteriores podemos hacer una primera aproximación al archivo del monasterio de Belmonte, de modo que estamos en situación de hacer una primera estimación sobre la actitud de los bernardos para con sus fondos documentales:

a) Disponen de un fondo organizado desde al menos la primera década del siglo $\mathrm{XVII}^{78}$, con la vieja documentación de pergamino dispuesta en cajoneras. De este modo, sabemos que ya desde entonces inicios del Seiscientos el archivo del monasterio cuenta con un armario similar a los que se conocen para otros depósitos documentales monásticos.

b) Lejos de un absoluto descuido desde entonces, el archivo fue objeto de sucesivas atenciones y la gestión de la documentación no fue del todo abandonada. Así, cierto celo pusieron los archiveros de los siglos XVII y XVIII, pues a mediados del siglo XVIII, Muñiz llegó a ver un archivo bien dispuesto.

c) Finalmente, cabe apuntar que el cumplimiento de las escasas medidas en materia archivística y documental tomadas en el seno de la Congregación cisterciense de Castilla, tales como la elaboración de un libro de gobierno (el becerro que manejan Jovellanos, Manrique o Baragaña) o la organización de los fondos documentales es una realidad en Belmonte entre los siglos XVI a XIX.

\section{FUENTES IMPRESAS}

Alonso Martín, M.a L. y Palacio Sánchez-Izquierdo, M.a L. 1993. Jurisdicción, gobierno y hacienda en el señorío de abadengo castellano en el siglo XVI. Estudio y edición de las informaciones de Carlos V de 1553. Madrid: Editorial Complutense - CSIC.

Argaiz, G. 1675. La Soledad Laureada. Tomo segundo. Madrid: Bernardo de Herbada.

Berganza, F. 1729. Ferreras convencido, con crítico desengaño en el tribunal de los doctos con los chronicones corregidos que escribieron el rey don Alonso III, dicho el magno, Sampiro, obispo de Astorga, Pelagio, obispo de Oviedo, Isidro, obispo pacense, el anónymo Iriense. Madrid: Francisco del Hierro. [sin foliar].

Caballero, M. 1995. Noticias documentales y genealógicas de Tineo. Edición de M. $\underline{a}$ J. Sanz Fuentes. Tineo: Ayuntamiento de Tineo.

Carvallo, L. A. 1988. Antigüedades y Cosas Memorables del Principado de Asturias. Gijón: Silverio Cañada editor.

Diffiniciones de la Orden de Cistel y Observancia de España. Salamanca: en Casa de Juan de Terranova, 1561.

Diffiniciones hechas en el Capítulo General que se celebró en el monasterio de Santa María la Real de Palaçuelos à cinco de mayo del año de 1611 en el qual salió por General Reformador nuestro Reverendíssimo padre maestro fray Philippe de Tassis, hijo del real monasterio de Herrera.

Falqué Rey, E. 1994. Historia Compostelana. Madrid: Akal.

Finestres y de Monsalvo, J. 1753. Historia de el Real monasterio de Poblet, ilustrada con Disertaciones Curiosas sobre la Antigüedad de su Fundación, Catálogo de Abades, y Memorias Chronológicas de sus Goviernos, con las de Papas, Reyes y Abades Generales de Cistèr tocantes à Poblet, dividida en quatro libros. Tomo I. Que contiene el Libro Primero de la Fundación y Descripción de

78 Esta organización ha sido objeto de estudio en Fernández Ortiz 2017: 359-407. 
el Monasterio, y una Exposición de los Vaticinios de los Reyes de León, Castilla y Aragón, y Príncipes de Cataluña. Cervera: Joseph Barber.

González Posada, C. 1989. Biblioteca Asturiana o Noticia de los Autores Asturianos. Edición Preparada por Marino Busto. Gijón: Editorial Auseva.

Jovellanos, G. M. 1948. Colección de Asturias mandada publicar por el Marqués de Aledo, tomo II, edición de M. Ballesteros Gaibrois. Madrid.

Jovellanos, M. G. 1985. Obra completa. Tomo II. Correspondencia 1‥ Gijón: Instituto Feijoo del Siglo XVIII.

Jovellanos, M. G. 1994. Obras Completas. Tomo VI. Diario I. Gijón: Instituto Feijoo del Siglo XVIII - Ayuntamiento de Gijón.

Llamas, J. 1993. Fundación y dotación del monasterio de Carracedo. Año 1593. Edición de Francisco González González. Ponferrada: Institución Virgen de La Encina.

Manrique, Á. 1649. Annalium a condito cistercio. Tomus quartus. Lyon: Laur. Anisson et al.

Manrique, Á. 1649. Cisterciensum, Seu verius Ecclesiasticorum Annalium a Condito Cistercio. Tomus Tertius, Continens ab Anno MCLXXIV usque ad MCCXII. Lugduni: Sumptibus Laurentij Anisson.

Miguel Vigil, C. 1887. Asturias monumental, epigráfica y diplomática. Oviedo: Imprenta del Hospicio Provincial.

Montejo, B. 1792. "Memorias históricas para la vida del ilustrísimo señor don fray Prudencio de Sandoval», en P. Sandoval, Historia de Los Reyes de Castilla y de León Don Fernando el Magno, primero de este nombre, Infante de Navarra. Don Sancho, que murió sobre Zamora. Don Alonso Sexto de este nombre. Sacada de los Previlegios, libros antiguos, memorias, diarios, piedras, y otras antiguallas, con la diligencia y cuidado que en esto pudo poner don fray Prudencio de Sandoval, obispo de Pamplona: 17-38. Madrid: Oficina de don Benito Cano.

Morales, A. 1765. Viage por orden del Rey D. Phelipe II a los Reynos de Leon y Galicia y Principado de Asturias, para reconocer las Reliquias de Santos Sepulcros Reales y Libros manuscritos de las Cathedrales y Monasterio. Madrid: Antonio Marín.

Muñiz, R. 1793. Biblioteca Cisterciense Española. En la que se da noticia de los escritores cistercienses de todas las Congregaciones de España, y de los de las Órdenes Militares que siguen el mismo instituto, con la expresión (en la mayor parte) del Lugar de nacimiento, Empleos, Honores, Dignidades, igualmente que el de sus Obras tanto impresas como $m$. ss. Burgos: Don Joseph de Navas.

Risco, M. 1789. España Sagrada. Tomo XXXVII. Antigüedades concernientes á la región de los Astures Transmontanos desde los tiempos más remotos hasta el siglo X. Establecimiento del Reyno de Asturias y memorias de sus reyes: Fundación de la Ciudad e Iglesia de Oviedo: noticias de sus primeros obispos y examen crítico de los Concilios ovetenses. Madrid: Oficina de Blas Román.

Rodríguez de Diego, J. L. 1989. Instrucción para el arreglo del Archivo de Simancas (año 1588). Madrid: Ministerio de Cultura.

Ruiz de la Peña Solar, J. I. y Sanz Fuentes, M.a J. 1991. Colección diplomática del Monasterio de San Vicente de Oviedo (siglos XIII-XV). I.1: 1201-1230. Oviedo.

Sandoval, P. 1600. Chrónica del ínclito emperador de España don Alonso VII deste nombre. Madrid: Luis Sánchez.

Sota, F. 1681. Chrónica de los Príncipes de Asturias y de Cantabria. Madrid: Juan García Infançón.

Trelles Villademoros, J. M. 1736. Asturias Ilustrada, origen de la nobleza de España, su Antigüedad, y diferencias. Dividida en tres tomos. Tomo Primero. Madrid: Imprenta de Joachín Sánchez.

Yepes, A. 1609. Corónica de la Orden de San Benito, Patriarca de Religiosos. Tomo VII. Irache: Matías Mares Impressor del Reyno de Navarra.

\section{REFERENCIAS BIBLIOGRÁFICAS}

Bautier, R. H. 1968. “'La phase cruciale de l'histoire des archives' la constitution des dépôts d'archives et la naissance de l'archivistique (XVI ${ }^{\mathrm{e}}$ - debut du XIXe siècle)». Archivum XVIII: 139-149.
Bouzá Álvarez, F. 2001. Corre manuscrito. Una historia cultural del Siglo de Oro. Madrid: Marcial Pons.

Calleja Puerta, M. 2007. "Trayectoria histórica de los estudios de Paleografía y Diplomática en Asturias». Boletín de Letras del Real Instituto de Estudios Asturianos 170: 91-121.

Canella Secades: F. 1903-1904. Historia de la Universidad de Oviedo y noticias de los establecimientos de enseñanza de su distrito (Asturias y León). Oviedo: Imprenta de Flórez.

Canellas López, Á. 1986. «El historiador Jerónimo Zurita», en Jerónimo Zurita. Su época y su escuela: 7-22. Zaragoza: Institución Fernando el Católico.

Canellas López, Á. 1994. "Historiografía y archivos aragoneses», en Actas de las IV Jornadas de Archivos Aragoneses: 15-27. Zaragoza: Diputación General de Aragón.

Castillo Gómez, A. 1997. Escrituras y escribientes. Prácticas de la Cultura Escrita en una ciudad del Renacimiento. Gran Canaria.

Cid Priego, C. 1990. "El obispo de Pamplona fray Prudencio de Sandoval, estudioso de la Cruz de los Ángeles de Oviedo». Príncipe de Viana 191: 771-784.

Cuartas Rivero, M. 1982. "La venta de lugares eclesiásticos en Asturias en el siglo XVI». Semana de Historia del monacato cántabro-asturleonés: 463-468. Oviedo: monasterio de San Pelayo.

Faya Díaz, M.a Á. 1993. Los señoríos eclesiásticos en la Asturias del siglo XVI. Oviedo: Ridea.

Fernández Ortiz, G. 2017: Historia y memoria. El monasterio de Santa María de Belmonte a través de su Tumbo Nuevo. Oviedo: Universidad de Oviedo.

Fernández Ruiz, C. 1965. Historia médica del Principado de Asturias. Oviedo: Instituto de Estudios Asturianos.

Fuertes Acevedo, M. 1878. «Discurso inédito del padre Carballo sobre la Merindad de Asturias con introducción, notas y una noticia biográfica del autor (continuación)». Revista de Asturias ilustrada. Científico-literaria 25: 289-292.

García Hernán, E. 2004. «Construcción de las historias de España en los siglos XVII y XVIII», en R. García Cárcel (coord.), La construcción de las historias de España: 127-194. Madrid: Marcial Pons.

García Hernán, E. 2006. «La España de los cronistas reales en los siglos XVI y XVII». Norba. Revista de Historia 19: 125-150.

García Oro, J. 1969. La reforma de los religiosos españoles en tiempo de los Reyes Católicos. Valladolid: Instituto Isabel la Católica.

García Oro, J. y Portela Silva, M.a J. 2001. Los monasterios de la Corona de Castilla en el reinado de Carlos V. Santiago de Compostela: Liceo Franciscano.

Garralda García, Á. 1970. Avilés, su fe y sus obras. Avilés.

González Gutiérrez, L. 1993. «El libro de Actas del Colegio de Belmonte». Correveidile. Periódico Comarcal 7: 9. [Oviedo: Belmonte Xoven Senda Editorial S. A.].

Mañana Vázquez, G. 2012. El Camino Real de la Mesa. Oviedo: CajAstur. Martín López, M.a E. 2011. Ángel Manrique y la Epigrafía medieval. León: «Corpus Inscriptionum Hispaniae Mediaevalium».

Martín, E. 1953. Los Bernardos españoles (Historia de la Congregación de Castilla de la Orden del Císter). Palencia: Gráficas Aguado.

Martínez Fernández, E. 1979. Los documentos asturianos del Archivo Histórico Nacional. Gijón: Ed. Auseva.

Menéndez González, A. 1983. «La desamortización eclesiástica en Asturias en la época de Felipe II. 1á parte». Boletín del Instituto de Estudios Asturianos 109-110: 489-516.

Mestre Sanchís. A. 2003. "La Erudición, del Renacimiento a la Ilustración», en Apología y crítica de España en el siglo XVIII: 239-265. Madrid: Marcial Pons.

Moro Barreñada, J. M. 1986. «La desamortización eclesiástica. Acceso de la burguesía a la propiedad de la tierra», en Historia General de Asturias. Siglo XIX 4: 97-112. Gijón: Silverio Cañada editor.

Pérez de Castro, J. L. 1959. El Diccionario Geográfico Histórico de Asturias dirigido por el doctor don Francisco Martínez Marina I. Génesis y colaboradores. Oviedo: Instituto de Estudios Asturianos.

Pérez de Urbel, J. 1959. "Estudio preliminar», en A. de Yepes, Crónica General de la Orden de San Benito. Madrid: Edidiciones Atlas. 
Pérez Recio, M. y Burón Castro, T. 2006. «El archivo de la catedral de León. Ensayo sobre su historia y organización», en F. Ramos y J. Paniagua Pérez (coords.), En torno a la catedral de León (estudios): 83-147. León: Universidad de León / Cabildo de la S. I. Catedral de León.

Pérez-Embid Wamba, F. J. 1986. El Císter en Castilla y León. Monacato y dominios rurales (siglos XII-XV). Valladolid: Junta de Castilla y León.

Pomian, K. 1972. "Les historiens et les archives dans la France du XVI siècle». Acta Poloniae Historica 26: 109-125.

Poncet, O. 2009. "L'histoire des évêques saisie par l'erudition (XVIleXVIIle siècles)", en M. Sot y F. Bougard (eds.), Liber, Gesta, histoire. Écrire l'histoire des évêques et des papes, de l'Antiquité au XXI siècle: 407-436. Turnhout: Brepols.

Poncet, O. 2010. «L'usage des chartriers seigneuriaux par les érudits et généalogistes en France dans la première moitié du XVII siècle», en L. Vissière y P. Contamine (eds), Défendre ses droits, construire sa mémoire. Les chartriers seigneuriaux XIIle-XXIe: 247-265. Paris: Société de l'Histoire de France.

Rodríguez de Diego, J. L. 1998. "Archivos del Poder, archivos de la Administración, archivos de la Historia (s. XVI-XVII)», en J.
J. Generelo y Á. Moreno (coords.), Historia de los archivos y de la archivística en España: 29-42. Valladolid: Universidad de Valladolid.

Rodríguez Díaz, E. E. 1994-1995. «Cultura escrita en Asturias: Sobre la lectura y los lectores de los manuscritos de la Catedral». Estudis Castellonencs, 6**. Miscellania d'estudis dedicats a la memòria del professor Josep Trechs i Òdena: 1167-1178.

Rueda Hernanz, G. 1997. La Desamortización en España: un balance (1766-1924). Madrid: Arco/Libros.

Santiago Fernández, J. 2012. «Comunicación publicitaria en el monasterio cisterciense de Nuestra Señora de Monsalud, en Córcoles (Guadalajara)». Hispania Sacra 129: 67-96.

Sastre Santos, E. 1995. Una instrucción de Jovellanos para el arreglo del archivo del monasterio santiaguista de Sancti Spiritus. Salamanca. 1790. Madrid: Hidalguía.

Suárez Fernández, C. 1956. Escritores y artistas asturianos: índice biobibliográfico. V. L-O. Oviedo: Instituto de Estudios Asturianos.

Yáñez Neira, M.a D. 2003. «Fray Roberto Muñiz, hijo ilustre de Avilés (1803-2003)». Boletín del Real Instituto de Estudios Asturianos 161: 49-70. 